\title{
NEW CONFIGURATIONS FOR HYBRID FILTERS TO IMPROVE POWER QUALITY
}

\author{
P Saraswathi $^{1}$, Karunakumar Davala ${ }^{2}$, M Karthika $^{3}$ \\ ${ }^{1}$ Assistant Professor, Department of Electrical Engineering, GRIET, AP, India \\ ${ }^{2}$ Assistant Professor, Department of Electrical Engineering, GRIET, AP, India \\ ${ }^{3}$ Assistant Professor, Department of Electrical Engineering, GRIET, AP, India
}

\begin{abstract}
Reforms in Power Sector have given an opportunity to the consumer to demand Quality Power. Unbalance, Distortion and poor regulation in the supply voltage have detrimental effect on the life of equipment and leads to poor efficiency in operation. Variable speed drives, Electric Traction and Furnace Loads inject harmonic currents into the supply system creating Bus voltage distortion. Even linear loads connected to this Bus will experience distorted load currents. These high frequency currents do not generate any useful output but produce over heating of motors, increased reactive power demand and ripples in the generated torque causing vibrations, leading to failure and poor performance efficiency. So there is a need for bypassing the load current harmonics generated by nonlinear loads from entering the system Bus Conventionally passive tuned filters connected to the Bus are used for bypassing the harmonics, but these filters have many limitations and become less effective under some operating conditions. Advent of high frequency, high power switching devices has given rise to new tools to mitigate the harmonic distortion in the Bus Voltage by freewheeling the harmonic currents, these are generally called as Active Filters. There are many configurations of these filters. Many of the limitations faced by tuned passive filters are overcome by the use of Active filters, but by combining the tuned and active filter the reliability and affectivity in improving power quality is enhanced, these are called Hybrid Filters. This paper briefly deals with two new configurations of Hybrid filter, one based on Pulse Width Modulation $(P W M)$ operated Voltage Source Converter and the other on Current Controlled Converter. Results of performance of these two filters applied to a simple distribution system with a nonlinear load are given.
\end{abstract}

Key words: Hybrid Filter, Current Harmonics, PWM

\section{INTRODUCTION}

Nonlinear loads such as diode or controlled rectifiers and inverters are widely used in industrial products. These circuits generate current harmonics and cause power pollution in the transmission or distribution system. Major power quality problems at the consumer end are due to the bus voltage distortion.

Passive filters have been widely used to absorb harmonic current of nonlinear loads due to their low cost and availability. However, passive filters suffer some drawbacks such as strong dependence on system impedance, susceptible to source and load resonance and the variation of filter characteristics due to aging. Active power filters [1], [3] have been developed to overcome the problems of passive filters. Although providing excellent compensation results, pure series and shunt active filters are not yet a costeffective solution due to many consumers. Consequently, hybrid filters [4] are attracting more and more attention. Various topologies, such as the combination of active and passive filters have been developed to combine the advantages of passive filters and active filters [5], [6]. This paper briefly deals with two new configurations of Hybrid filter, one based on PWM operated Voltage Source Converter and the other on Current Controlled Converter.
These two hybrid filters are applied to single-phase and three-phase nonlinear loads and the performance results are reported.

\section{PRICIPLE OF OPERATION OF HYBRID VOLTAGE FED INVERTER}

The configuration of the proposed hybrid filter for both single phase and three phase systems are shown in Fig.1 and Fig. 2. It consists of an active power filter and passive filter. In this configuration passive filters are tuned at $150 \mathrm{~Hz}$ for single phase and $250 \mathrm{~Hz}$ for three phase to suppress part of harmonic currents caused by non linear loads and compensate load reactive power to improve the power factor. The modulation techniques not only allow controlling the inverters as voltage sources or as current sources generating proper gating signals for the active filter. PWM techniques are applied to the inverter. There are a large number of PWM techniques available to synthesize Sinusoidal patterns or any arbitrary pattern. With PWM techniques, the ac output of the filter can be controlled as a voltage source device. The inverter output voltage is identical to the control voltage that is applied to the bus through the tuned $3^{\text {rd }}$ harmonic filter for single phase and $5^{\text {th }}$ harmonic filter for three phase system. 


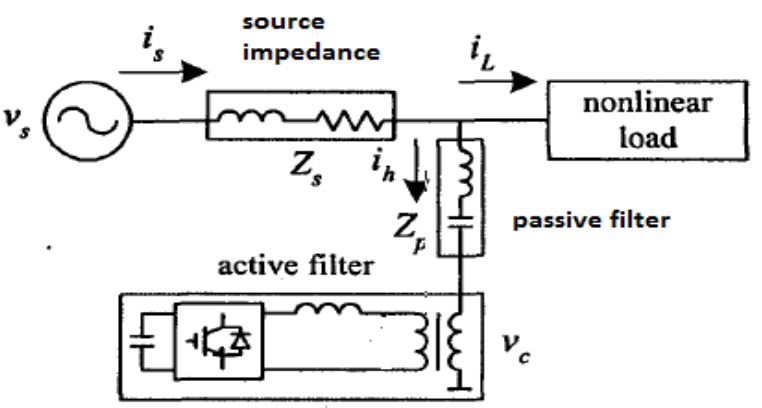

Fig -1:. Hybrid active filter for single phase load

\section{SIMULATION RESULTS OF VOLTAGE FED METHOD}

Detailed simulation study has been carried out for single phase and three phase hybrid voltage fed filter. Simulation results are given with and without voltage fed hybrid filter. Source current magnitudes, THD values and their corresponding waveforms before and after compensation for single phase and three phase systems are given in this section. The system parameters for single phase and three phase are given in Tables I and II

Table- I: Parameters of the single phase system

\begin{tabular}{|c|l|l|}
\hline S.No & \multicolumn{1}{|c|}{ Parameter } & \multicolumn{1}{|c|}{ Value } \\
\hline 1 & Source voltage Vs & $230 \mathrm{Vrms}$ \\
\hline 2 & Source impedance $\mathrm{Zs}$ & $0.27 \Omega$ \\
\hline 3 & Passive load parameters & $\mathrm{R}=0.1 \Omega$ \\
& & $\mathrm{L}=0.05 \mathrm{H}$ \\
\hline 4 & $\begin{array}{l}\text { Passive filter tuned for } \\
3^{\text {rd }} \text { harmonic }\end{array}$ & $\mathrm{L}=18 \mathrm{mH}$ \\
$\mathrm{C}=60 \mu F$ \\
\hline 5 & Rectifier load & $\mathrm{R}=10 \Omega$ \\
& parameters & $\mathrm{L}=100 \mathrm{mH}$ \\
\hline
\end{tabular}

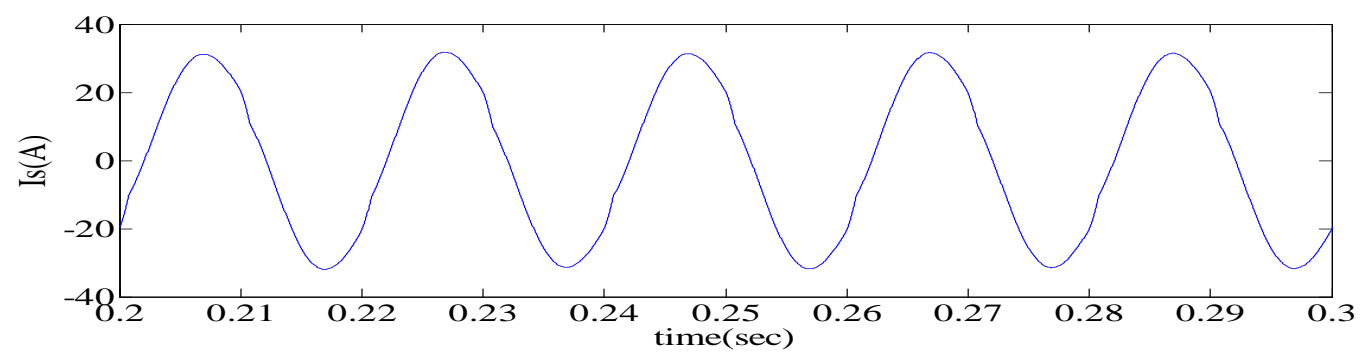

Fig -2: Single phase system

Table-2: Parameters of the three phase system

\begin{tabular}{|c|l|l|}
\hline S. No & \multicolumn{1}{|c|}{ Parameter } & \multicolumn{1}{c|}{ Value } \\
\hline 1 & Source voltage Vs & $415 \mathrm{Vrms}$ \\
\hline 2 & Source impedance Zs & $0.52 \Omega$ \\
\hline 3 & Passive load parameters & $\begin{array}{l}\mathrm{R}=0.1 \Omega \\
\mathrm{L}=0.05 \mathrm{H}\end{array}$ \\
\hline 4 & $\begin{array}{l}\text { Passive filter tuned for } 5^{\text {th }} \\
\text { harmonic }\end{array}$ & $\begin{array}{l}\mathrm{L}=6.75 \mathrm{mH} \\
\mathrm{C}=60 \mu F\end{array}$ \\
\hline 5 & Rectifier load parameters & $\begin{array}{l}\mathrm{R}=10 \Omega \\
\mathrm{L}=100 \mathrm{mH}\end{array}$ \\
\hline & & \\
\hline
\end{tabular}

\subsection{Single phase system}

Single phase system results without filter are shown in Fig- 3.

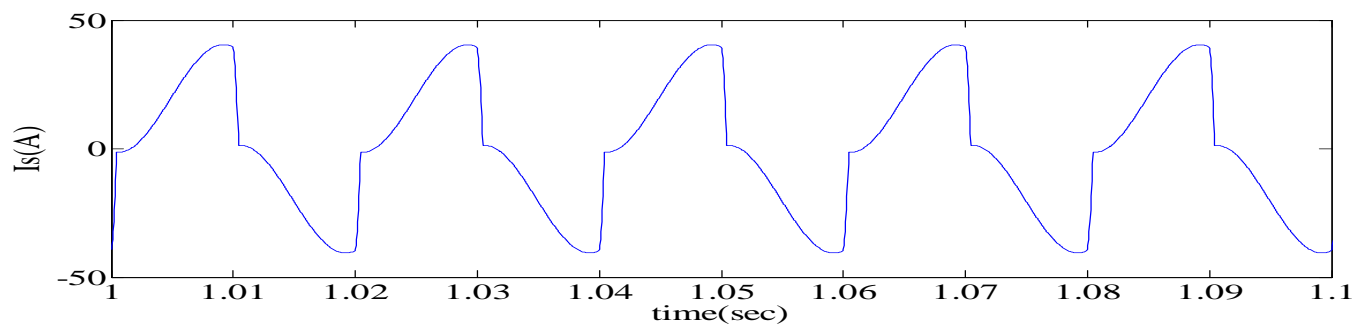

(a) 




(b)

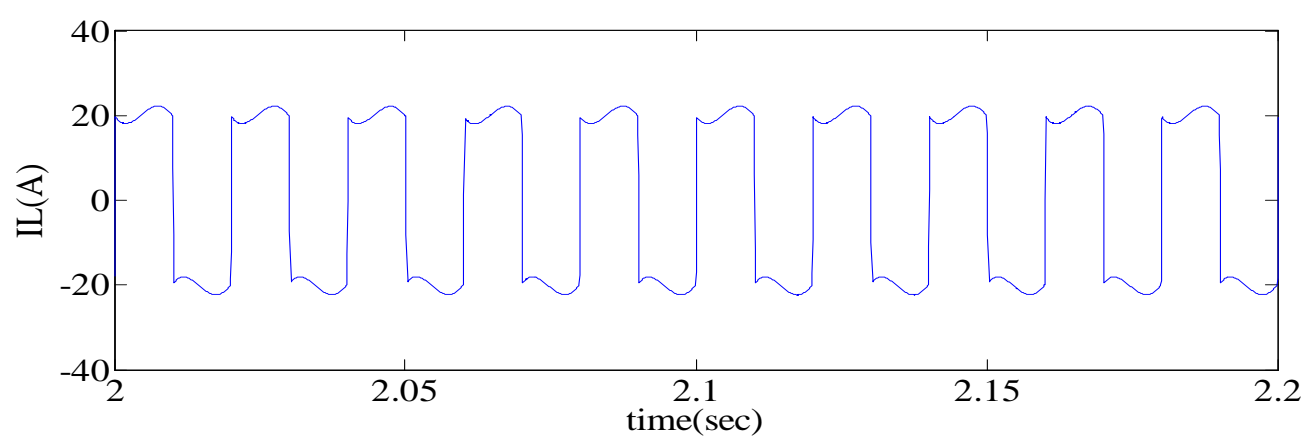

(c)

Fig-3: Single phase system results without filter (a) Source current, (b) Source voltage and current, (c) Load current.

Simulation results of single phase systemesults with Hybrid Filter are shown in Fig. 4.

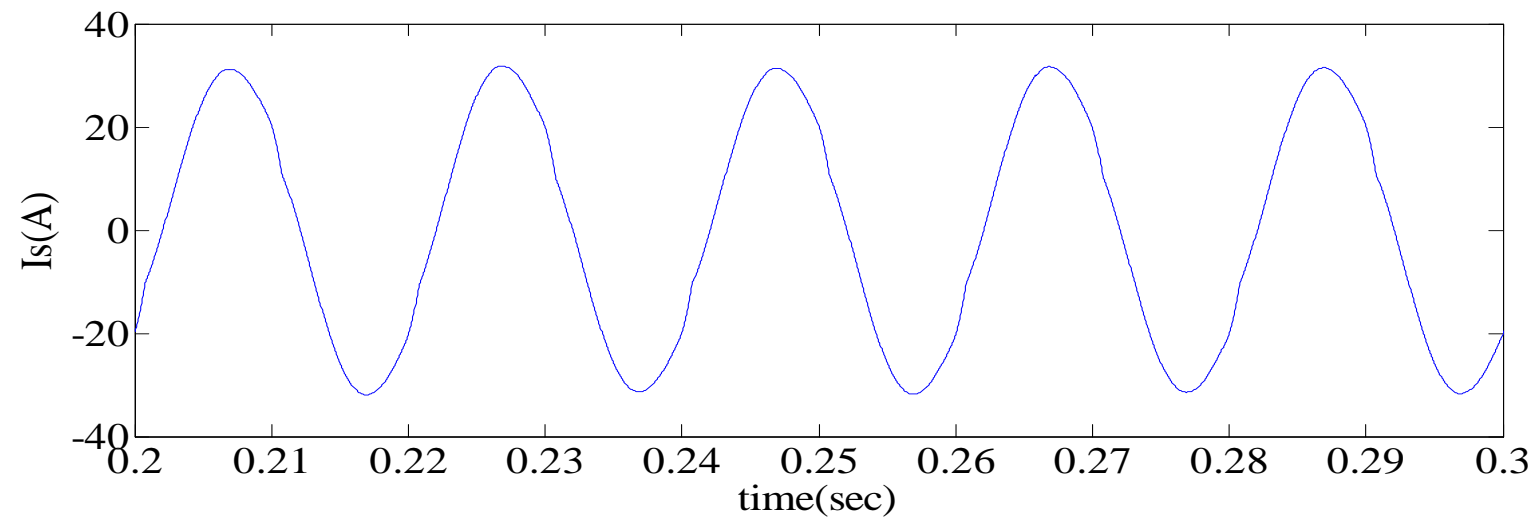

(a)



(b)

Fig-4: Single phase system results with hybrid filter (a) Source current, (b) Source voltage and current. 
Performance results are given in table III for a single phase system with Non Linear Load for with out and with filter configurations. The control voltage for the PWM operation of VSC is derived from the load current harmonics obtained through passive filters. The methodology used to extract the harmonic current $\left(\mathrm{I}_{h}\right)$ using passive filter tuned filters is shown in Fig. 5. The control voltage ' $\mathrm{V}_{\mathrm{c}}$ ' is equal to $\mathrm{K}$. $\mathrm{I}_{\mathrm{h}}$. It can be seen from the results the source power factor is improved from 0.72 to 0.8 and the source current THD is reduced from $30.53 \%$ to $2.22 \%$. To improve power factor further the control voltage is augmented by a portion of the source voltage. Simulation results with voltage fed hybrid filter are shown in Fig. 6

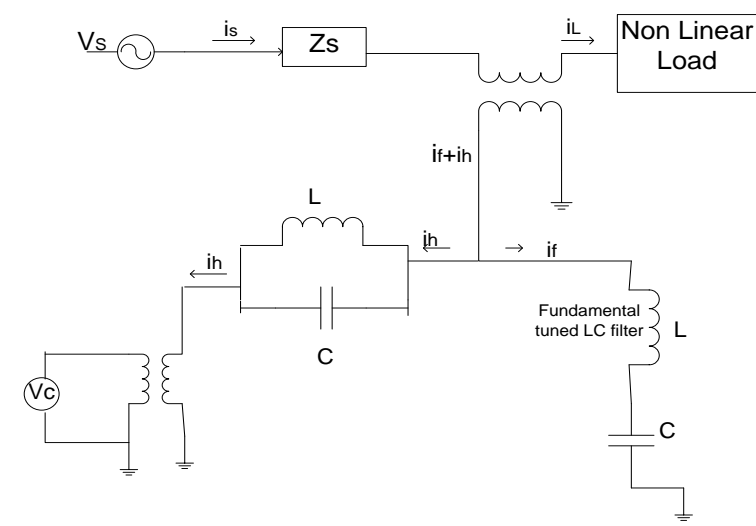

Fig-5: Extraction of current harmonics

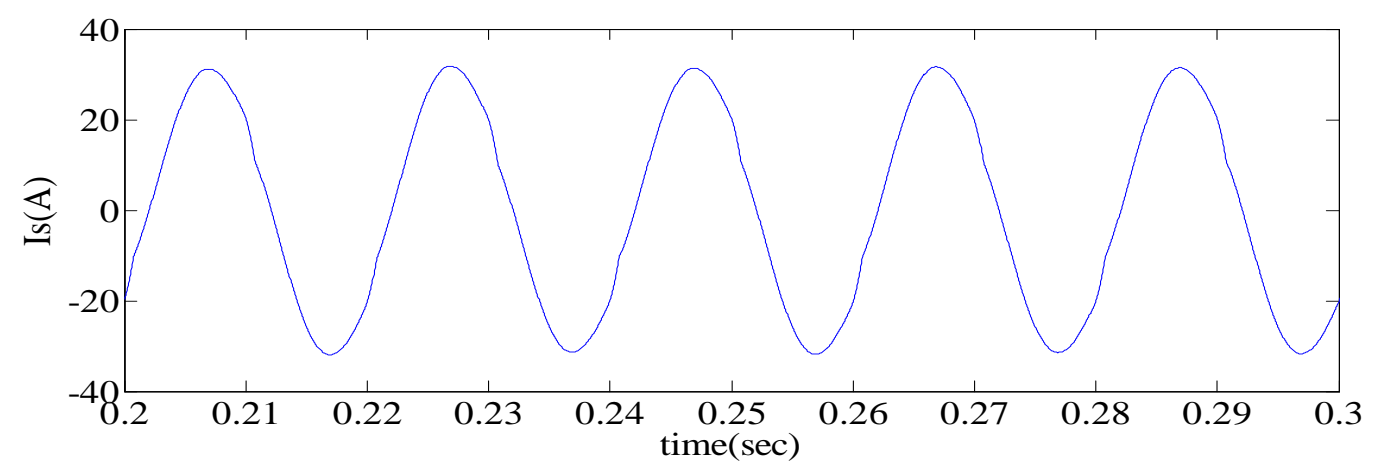

(a)

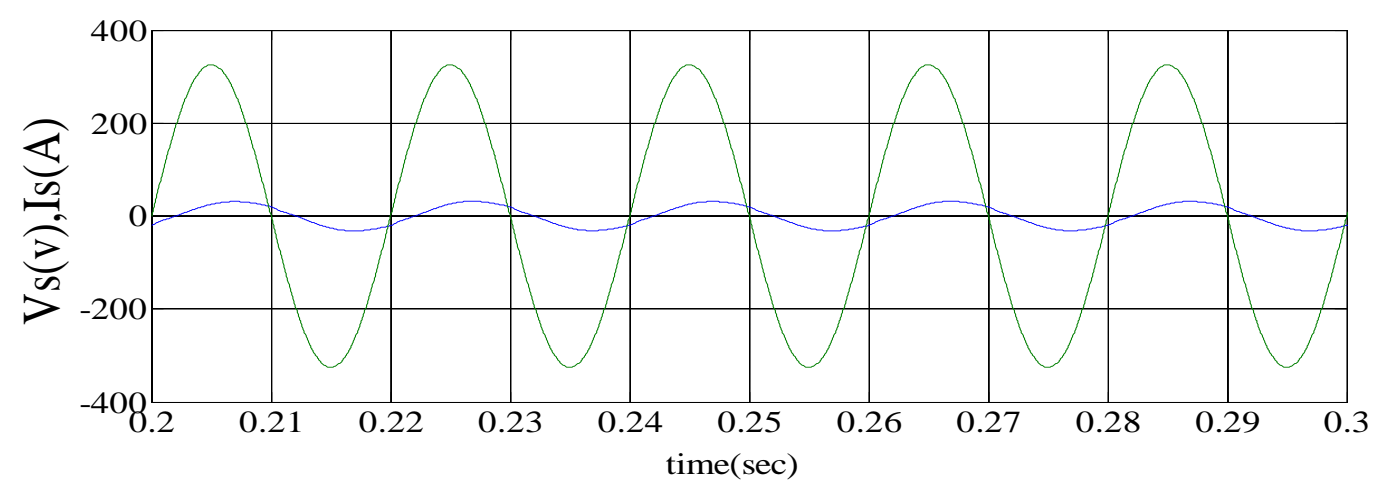

(b)

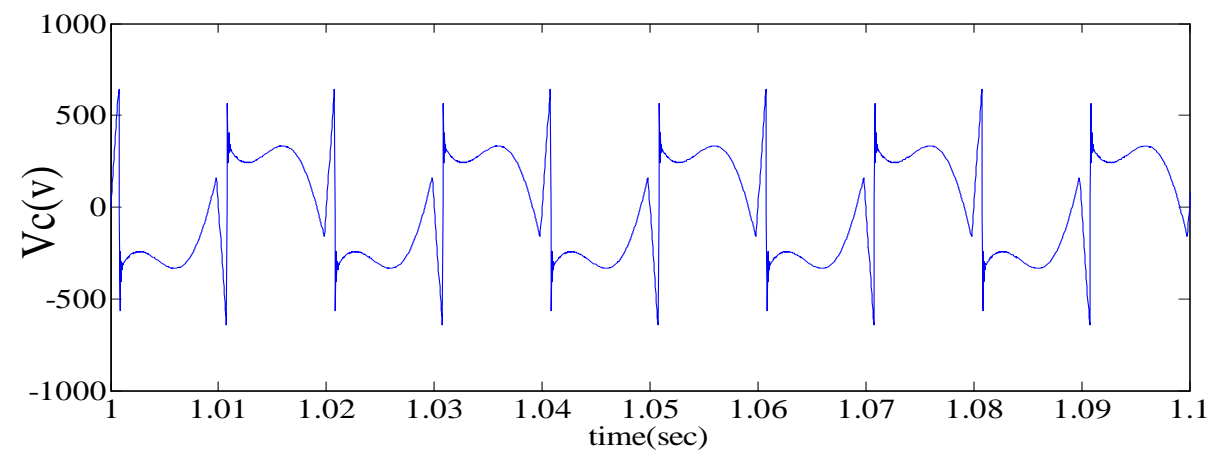

(c)

Fig-6: Single phase system results with voltage fed hybrid filter (a) Source current, (b) Source voltage and current, (c) Controlled voltage. 
Table -3:Single phase system results

\begin{tabular}{|c|c|c|c|c|}
\hline \multirow[t]{2}{*}{ S.No } & \multirow[t]{2}{*}{ Method } & \multicolumn{2}{|l|}{ Source current } & \multirow{2}{*}{$\begin{array}{l}\text { Power } \\
\text { factor } \\
\operatorname{Cos} \Phi\end{array}$} \\
\hline & & $\begin{array}{c}\text { Peak } \\
\text { Magnitude(A) }\end{array}$ & $\begin{array}{c}\text { THD } \\
(\%)\end{array}$ & \\
\hline 1. & $\begin{array}{l}\text { Single phase } \\
\text { source with } \\
\text { Diode bridge } \\
\text { rectifier }\end{array}$ & 35.33 & 30.53 & 0.72 \\
\hline 2. & $\begin{array}{l}\text { With 3rd } \\
\text { harmonic LC } \\
\text { filter } \\
\text { compensation }\end{array}$ & 31.62 & 2.22 & 0.8 \\
\hline
\end{tabular}

\subsection{Three phase system}

Three phase system results without filter are shown in Fig. 7.

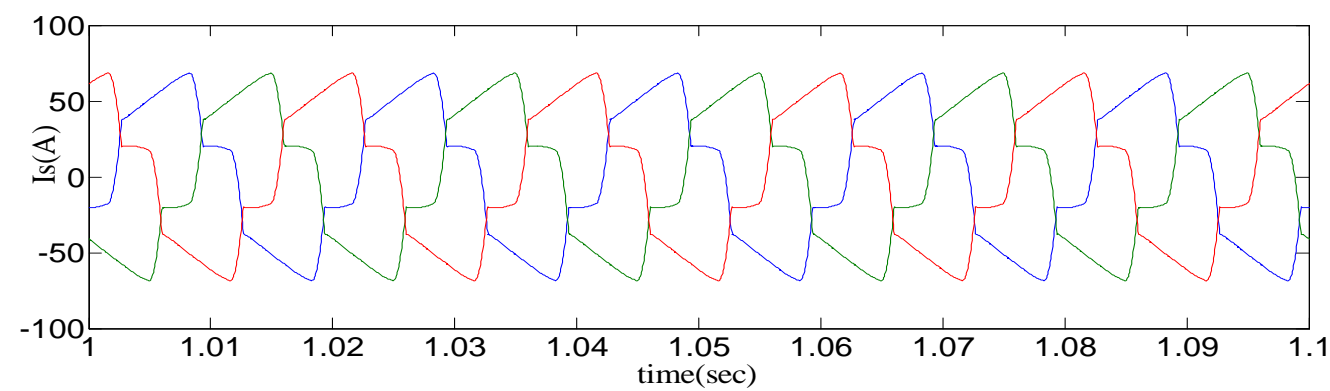

(a)

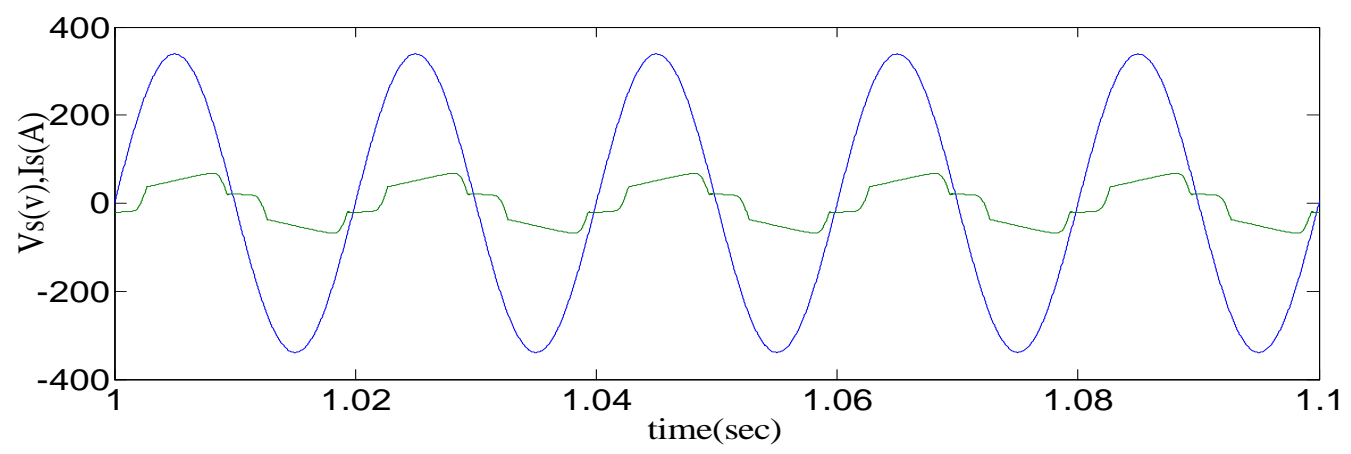

(b)

Fig-7: Three phase system results without filter (a) Three phase Source currents, (b) Source voltage and current Simulation results of three phase system with hybrid filter are shown in Fig. 8.

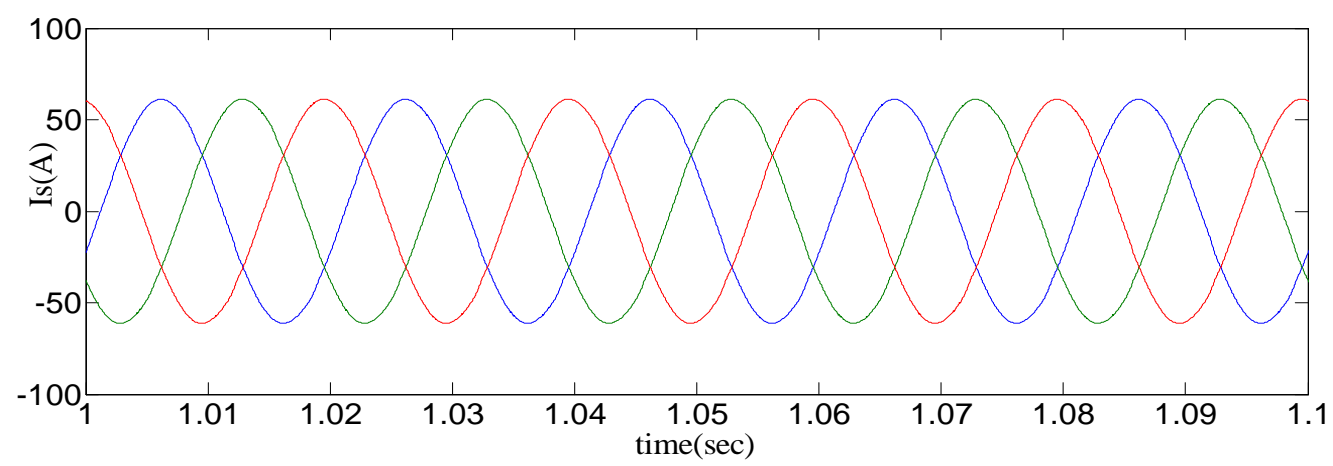

(a) 


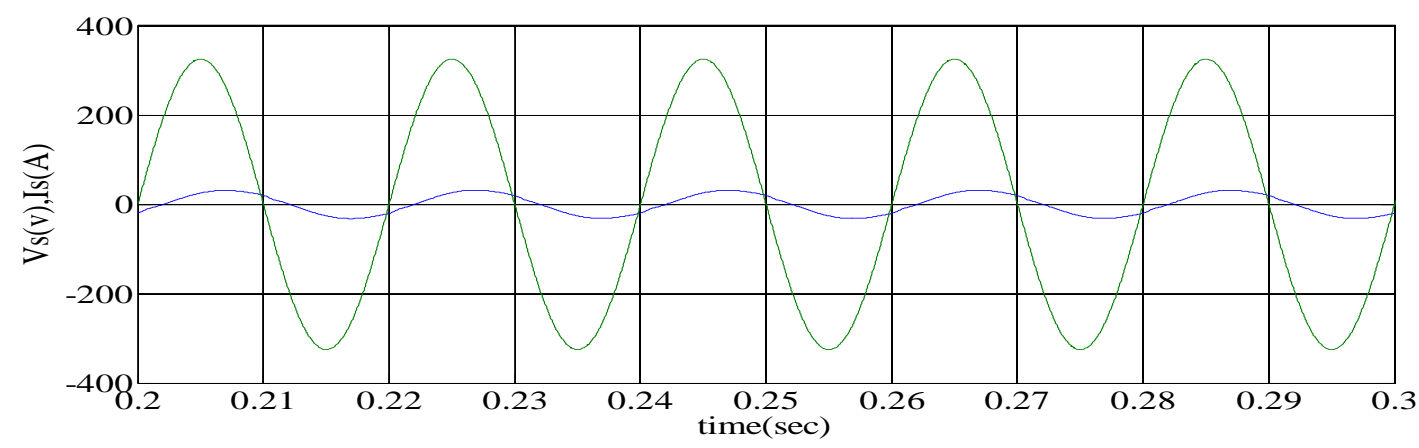

(b)

Fig-8: Three phase system results with voltage fed hybrid filter (a) Three phase Source currents, (b) Source voltage and current.

Simulation results of three phase system with the augumented control voltage are shown in Fig. 9 .



(a)

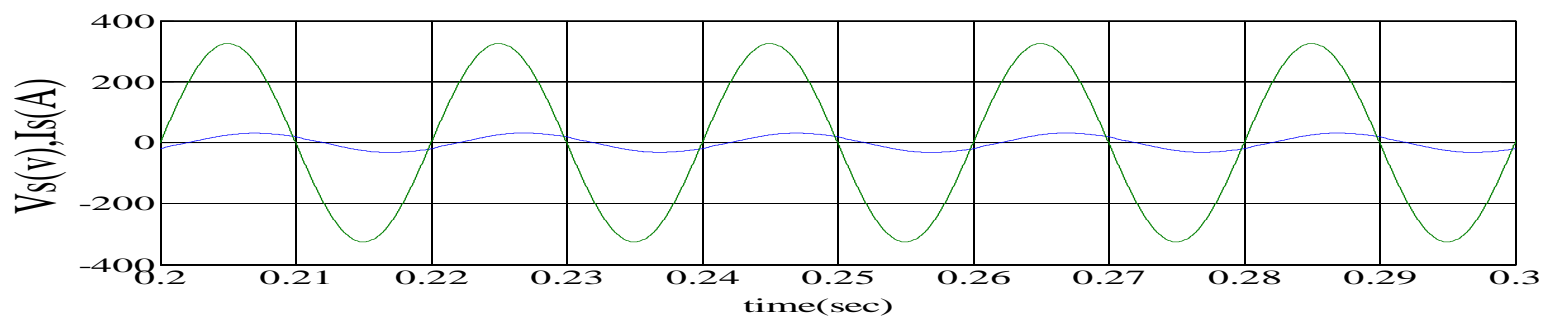

(b)

Fig-9: Three phase system results with augmented control hybrid filter (a) Three phase Source currents, (b) Source voltage and current.

The performance results of three phase system are given in Table IV.

Table-4: Three phase system results

\begin{tabular}{|c|c|c|c|c|}
\hline \multirow[t]{2}{*}{ S.NO } & \multirow[t]{2}{*}{ Method } & \multicolumn{2}{|c|}{ Source current } & \multirow{2}{*}{$\begin{array}{l}\text { Power } \\
\text { factor } \\
\operatorname{Cos} \Phi\end{array}$} \\
\hline & & $\begin{array}{c}\text { Peak } \\
\text { Magnitude(A) }\end{array}$ & $\begin{array}{c}\text { THD } \\
(\%)\end{array}$ & \\
\hline 1. & $\begin{array}{l}\text { Three phase source } \\
\text { with Diode bridge } \\
\text { rectifier }\end{array}$ & 63.46 & 20.67 & 0.86 \\
\hline 2. & $\begin{array}{l}\text { With } 5^{\text {th }} \text { harmonic } \\
\text { LC filter } \\
\text { compensation }\end{array}$ & 61.17 & 0.61 & 0.93 \\
\hline 3. & $\begin{array}{l}\text { With additional } \\
\text { voltage injection } \\
\left(\mathrm{V}_{\mathrm{c}}-1 . \mathrm{V}_{\mathrm{m}} \operatorname{sinwt}\right)\end{array}$ & 59.34 & 0.61 & 0.96 \\
\hline
\end{tabular}

From table IV, it can be seen that source current THD is reduced to $0.61 \%$ and also the power factor of the system improved to 0.96 with additional voltage injection.

\section{PRINCIPLE OF OPERATION OF HYBRID CURRENT FED INVERTER}

The configuration of the proposed hybrid filter for both single phase and three phase are shown in Fig. 10 and Fig. 11. Hysteresis control method is used to ensure that the injected current by the inverter almost follows the reference current derived from load current harmonics. 


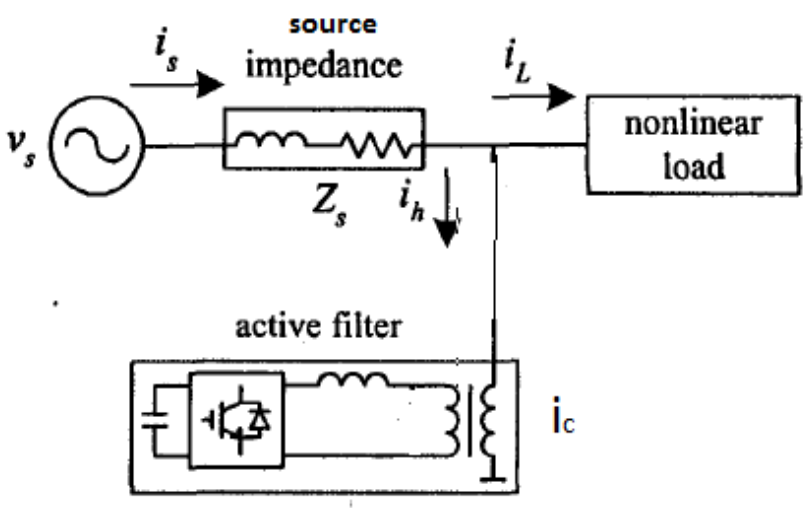

Fig-10. Single phase system compensated with current fed

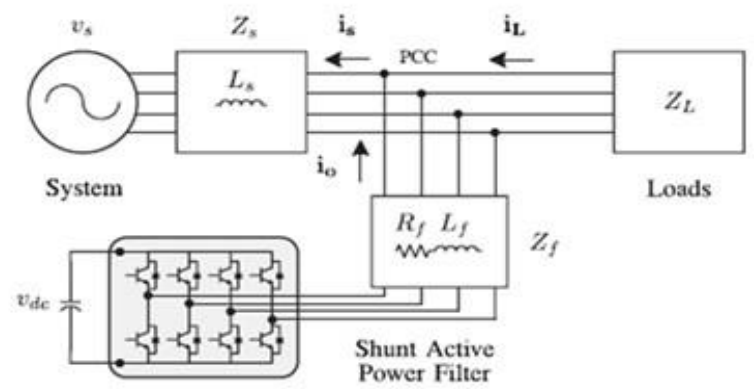

Fig-11: Three phase system compensated with current fed hybrid filter

Similar to the voltage fed case here also to improve the source power factor the reference current is augumented

with the power frequency reactive component of the source current as given by the "Equation. (1)".

$$
i_{c}=K_{1} \cdot i_{s h}+K_{2} \cdot \operatorname{Sin}(-\varnothing) \cdot \operatorname{Cos} \omega t
$$

\section{SIMULATION RESULTS OF CURRENT FED HYBRID FILTER}

Detailed simulation study has been carried out for single phase and three phase hybrid current fed method. Simulation results are shown with and without current fed hybrid filter. The augmented current waveform is shown in Fig. 12. Source current magnitudes, THD values before and after compensation are given in Table $\mathrm{V}$ for single phase case and in Table VI for three phase case.

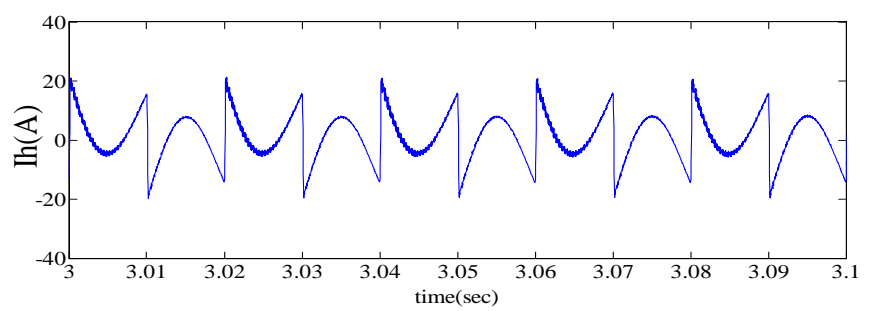

Fig-12: Augmented current waveform
Table-5: Single phase system results with current fed Hybrid Filter

\begin{tabular}{|c|l|c|c|c|}
\hline S.No & \multicolumn{1}{|c|}{ Method } & \multicolumn{2}{|c|}{ Source current } & $\begin{array}{c}\text { Power } \\
\text { factor } \\
\text { Cos } \Phi\end{array}$ \\
\cline { 3 - 4 } & $\begin{array}{c}\text { Peak } \\
\text { Magnitude } \\
(\mathrm{A})\end{array}$ & $\begin{array}{c}\text { THD } \\
(\%)\end{array}$ & \\
\hline 1. & $\begin{array}{l}\text { Single phase source } \\
\text { with Diode bridge } \\
\text { rectifier }\end{array}$ & 35.33 & $\begin{array}{c}30.5 \\
3\end{array}$ & 0.72 \\
\hline 2. & $\begin{array}{l}\text { With Current } \\
\text { compensation }\end{array}$ & 28.67 & 3.73 & 0.91 \\
\hline 3. & $\begin{array}{l}\text { With augmented } \\
\text { current injection } \\
\mathrm{K}_{1} * \mathrm{I}_{\mathrm{h}}- \\
\left(\mathrm{K}_{2} * \text { Isinథcoswt }\right)\end{array}$ & 24.18 & 4.16 & 0.99 \\
\hline
\end{tabular}

Table-6: Three phase system results with current Fed hybrid

\begin{tabular}{|c|c|c|c|c|}
\hline \multirow{3}{*}{ S.No } & \multirow{3}{*}{ Method } & \multirow{2}{*}{\multicolumn{2}{|c|}{ Source current }} & \multirow{3}{*}{$\begin{array}{l}\text { Power } \\
\text { factor } \\
\text { Cos } \Phi\end{array}$} \\
\hline & & & & \\
\hline & & $\begin{array}{l}\text { Peak } \\
\text { Magnitud } \\
\text { e } \\
\text { (A) }\end{array}$ & $\begin{array}{l}\text { THD } \\
(\%)\end{array}$ & \\
\hline 1. & $\begin{array}{l}\text { Three phase } \\
\text { source with } \\
\text { Diode bridge } \\
\text { rectifier }\end{array}$ & 63.46 & 20.67 & 0.86 \\
\hline 2. & $\begin{array}{l}\text { With current } \\
\text { compensation }\end{array}$ & 60.26 & 2.46 & 0.97 \\
\hline 3. & $\begin{array}{l}\text { With augmented } \\
\text { current } \\
\text { injection } \\
\mathrm{K}_{1} * \mathrm{I}_{\mathrm{h}}- \\
\left(\mathrm{K}_{2} * \mathrm{I} \sin \Phi \cos w \mathrm{t}\right)\end{array}$ & 64.13 & 2.39 & 0.99 \\
\hline
\end{tabular}

From table V and VI, it can be seen that source current THD is reduced and also the power factor of the system is improved.

\section{CONCLUSION}

This paper investigates two new hybrid power filter configurations one is with PWM operated Voltage Source Converter and the other one with Current Controlled Converter. The analysis shows that these filters are characterized by well filtering performance. The control strategy is simple and practical. The load current harmonics are extracted using passive filters tuned to fundamental frequency. The two filters are applied to a simple distribution system with a nonlinear load for both single phase and three phase system. Simulation results show that the system power factor and the harmonics compensation performance are improved 


\section{ACKNOWLEDGEMENT}

The authors wish to express their gratitude to "Dr.M.Ramamoorty", Distinguished Professor, for his invaluable guidance and involvement in the project. The first author is fortunate to work under him, who is an inspiring creative researcher par excellence. The first author would like to express her sincere thanks for the encouragement and support extended by Dr. K. Anuradha and D.Ravi kumar.

\section{REFERENCES}

[1] Tarunjain, Shailendra jain, Ganga Agnihotri, "Comparison of topologies of hybrid active power filter", IET-UK International conference on Information and communication technology in Electrical Sciences (ICTES 2007), Dec.20-22,2007, Dr.M.G.R.University, Chennai, pp. 503-509.

[2] Hugh Rudnick, Juan Dixon and Luis Morán, "Delivering Clean and Pure power Active power filters as a solution to power quality problems in distribution networks", IEEE Power \& energy magazine, September/October 2003, pp.32-40.

[3] Xiang-Yang Xia, Xu Han, "A Novel Active Power Filter for Harmonic Suppression and Reactive Power Compensation", college of electrical engineering, Changsha University of science and Technology, ICIEA 2006.

[4] ZHAO Wei, LUO An, PENG Jianchun, DENG Xia, PENG ke, "A New Hybrid Filter for harmonic suppression and Reactive Power Compensation", China,CICED2008,Technical Session 2, power Quality and Power Conservation, pp.1-7.

[5] Hirofumi Akagi, "The State-of-the-Art of Active Filters for Power Conditioning", EPE2005-Dresden ISBN:90-75815-08-5, pp. 1-15.

[6] Bhim Singh , Kamal Al-Haddad, senior member, IEEE, and Ambrish Chandra, Member, IEEE, "A Review of Active Filters for Power Quality Improvement", IEEE Transactions on Industrial Electronics, Vol 46, No.5, October 1999, pp. 960972. 